\title{
Performance Improvement of a PMSM Sensorless Control Algorithm Using a Stator Resistance Error Compensator in the Low Speed Region
}

\author{
Nung-Seo Park*, Min-Ho Jang*, Jee-Sang Lee**, Keum-Shik Hong***, and Jang-Mok Kim ${ }^{\dagger}$ \\ * Advanced Group, HA Control R\&D Lab, LG Electronics Inc., Changwon, Korea \\ ${ }^{* * *}$ School of Electrical Eng., Pusan National University, Busan, Korea \\ *** School of Mechanical Eng., Pusan National University, Busan, Korea
}

\begin{abstract}
Sensorless control methods are generally used in motor control for home-appliances because of the material cost and manufactureing standard restrictions. The current model-based control algorithm is mainly used for PMSM sensorless control in the home-appliance industry. In this control method, the rotor position is estimated by using the $d$-axis and $q$-axis current errors between the real system and a motor model of the position estimator. As a result, the accuracy of the motor model parameters are critical in this control method. A mismatch of the PMSM parameters affects the speed and torque in low speed, steadystate responses. Rotor position errors are mainly caused by a mismatch of the stator resistance. In this paper, a stator resistance compensation algorithm is proposed to improve sensorless control performance. This algorithm is easy to implement and does not require a modification of the motor model or any special interruptions of the controller. The effectiveness of the proposed algorithm is verified through experimental results.
\end{abstract}

Key Words: Parameter estimation, Permanent magnet synchronous motor, Rotor position estimation, Sensorless control

\section{INTRODUCTION}

As energy costs increase, home-appliances such as washing machines and dish washers are being developed in the direction of having high efficiency and a high power factor through energy savings. Also, manufactures are trying to miniaturize appliances and reduce their cost by removing position and speed sensors. The PMSM (Permanent Magnet Synchronous Motor) is widely used in home-appliances due to its high torque density per unit volume and its wide controllable speed region.

In general, by using a phase control method, vector control can minimize the transient response and obtain a fast control response in dynamic acceleration and deceleration at high speeds. However, a high resolution position and speed sensor is indispensable for controlling a PMSM because vector control needs accurate position information. However, applying position and speed sensors to home-appliances is quite difficult due to the limitations in size, cost, maintenance, and reliability. As a result, many sensorless control schemes have been considered for the vector control of PMSMs without using

\footnotetext{
Manuscript received Apr. 12, 2010; revised Jul. 1, 2010

† Corresponding Author: jmok@pusan.ac.kr

Tel: +82-51-510-2366, Fax: +82-51-513-0212, Pusan Nat'l Univ.

* Advanced Group, HA Control R\&D Lab, LG Elec. Inc., Korea

** School of Electrical Eng., Pusan Nat'l Univ., Korea

*** School of Mechanical Eng., Pusan Nat'l Univ., Korea
}

a position or a speed sensor. Among them, the current modelbased control algorithm is popular in industry because the algorithm can be implemented easily and is robust in load torque.

Traditional sensorless algorithms estimate position and speed using the phase current and the phase voltage obtained from the PMSM [1]. For robust driving of PMSM sensorless vector control, accurate information on the estimated rotor position and speed is critical. Furthermore, the sensorless algorithm performance depends on the calculation process of the rotor position and speed information.

Since sensorless methods, which estimate the PMSM rotor position and speed, use an integrator, the methods have low performance in transient response when an error happens. In addition, they have difficulty in estimating rotor position and speed in the low-speed region because of the offset and drift components in the acquired feedback signals, the voltage distortions caused by the nonlinear behavior of the switching converter, and the errors due to the variations in the stator resistance and the back-emf constant which depend on the variations in the speed and load [2].

In this paper, a rotor position error occurred due to the variations of the stator resistance. The control of the current model-based sensorless is verified using a mathematical analysis in order to solve a low dynamic performance problem cased by variations in the stator resistance due to a variety of 


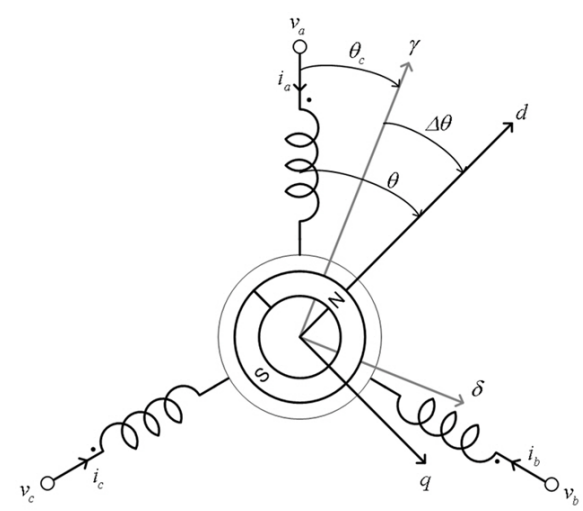

Fig. 1. The Analytical modeling of PMSM.

driving conditions. Then, a stator resistance error compensator is proposed to compensate for this rotor position error. The improvements in transient response and stability are verified through several actual experiments in the low speed region.

\section{Current Model-based Sensorless Control [3]}

In the current model-based sensorless control algorithm, the estimation of the position and speed are performed using the current error between the actual current and the model current. First of all, in the synchronous reference frame, the PMSM voltage equations are obtained as follows:

$$
\left[\begin{array}{l}
v_{d} \\
v_{q}
\end{array}\right]=\left[\begin{array}{cc}
R_{s}+p L_{s} & -L_{s} \dot{\theta} \\
L_{s} \dot{\theta} & R_{s}+p L_{s}
\end{array}\right]\left[\begin{array}{l}
i_{d} \\
i_{q}
\end{array}\right]+K_{E} \dot{\theta}\left[\begin{array}{l}
0 \\
1
\end{array}\right]
$$

where, $\dot{\theta}=\frac{d \theta}{d t}$ is the rotor angular frequency, $K_{E}$ is the backEMF constant, and $R_{S}$ and $L_{S}$ are the stator resistance and the stator inductance, respectively.

To estimate the PMSM rotor position, the controller configures an another current model of a PMSM based on the estimated rotor position angle.

$$
\left[\begin{array}{c}
v_{\gamma} \\
v_{\delta}
\end{array}\right]=\left[\begin{array}{cc}
R_{s}+p L_{s} & -L_{s} \dot{\theta} \\
L_{s} \dot{\theta} & R_{s}+p L_{s}
\end{array}\right]\left[\begin{array}{c}
i_{\gamma} \\
i_{\delta}
\end{array}\right]+K_{E} \dot{\theta}\left[\begin{array}{c}
-\sin \Delta \theta \\
\cos \Delta \theta
\end{array}\right]
$$

where, $\dot{\theta}_{c}=\frac{d \theta_{c}}{d t}$ is the estimated rotor angular frequency and $\Delta \theta=\theta-\theta_{c}$ is the angular error.

The angular error $\Delta \theta$ is the difference between the $d-q$ axis and the $\gamma-\delta$ axis. The position error is calculated by setting the angular error control to 0 .

When the current sampling period is much shorter than the time constant of the amarture winding, the voltage equation is converted to a current equation. The actual measured current equation from the converted $\gamma-\delta$ axis is obtained as follows:

$$
\begin{aligned}
& {\left[\begin{array}{l}
i_{\gamma}^{n+1} \\
i_{\delta}^{n+1}
\end{array}\right]=} \\
& {\left[\begin{array}{l}
i_{\gamma}^{n} \\
i_{\delta}^{n}
\end{array}\right]+\frac{T}{L_{s}}\left[\left[\begin{array}{l}
v_{\gamma} \\
v_{\delta}
\end{array}\right]-\left[\begin{array}{cc}
R_{s} & -L_{s} \dot{\theta}_{c} \\
L_{s} \dot{\theta}_{c} & R_{s}
\end{array}\right]\left[\begin{array}{l}
i_{\gamma} \\
i_{\delta}
\end{array}\right]-e\left[\begin{array}{c}
-\sin \Delta \theta \\
\cos \Delta \theta
\end{array}\right]\right]}
\end{aligned}
$$

where, $T$ is the current sampling period and $e=K_{E} \dot{\theta}$ is the actual PMSM back-EMF.

Also, for comparison with the measured $\gamma-\delta$ axis current, the estimated current of the $\gamma-\delta$ axis can be expressed as:

$$
\begin{aligned}
& {\left[\begin{array}{l}
i_{\gamma M}^{n+1} \\
i_{\delta M}^{n+1}
\end{array}\right]=} \\
& {\left[\begin{array}{l}
i_{\gamma}^{n} \\
i_{\delta}^{n}
\end{array}\right]+\frac{T}{L_{s}}\left[\left[\begin{array}{l}
v_{\gamma} \\
v_{\delta}
\end{array}\right]-\left[\begin{array}{cc}
R_{s} & -L_{s} \dot{\theta}_{c} \\
L_{s} \dot{\theta}_{c} & R_{s}
\end{array}\right]\left[\begin{array}{l}
i_{\gamma} \\
i_{\delta}
\end{array}\right]-e_{c}\left[\begin{array}{l}
0 \\
1
\end{array}\right]\right]}
\end{aligned}
$$

where, $i_{\gamma M}^{n+1}$ and $i_{\delta M}^{n+1}$ are $\gamma-\delta$ axis currents of the estimated model.

The position error is obtained by using the difference between the measured current in Equation (3) and the estimated current in Equation (4).

$$
\left[\begin{array}{l}
\Delta i_{\gamma}^{n+1} \\
\Delta i_{\delta}^{n+1}
\end{array}\right]=\left[\begin{array}{c}
i_{\gamma}^{n+1}-i_{\gamma M}^{n+1} \\
i_{\delta}^{n+1}-i_{\delta M}^{n+1}
\end{array}\right]=\frac{T}{L_{s}}\left[\begin{array}{c}
e \cdot \sin \Delta \theta \\
-\left(e \cdot \cos \Delta \theta-e_{c}\right)
\end{array}\right]
$$

where, $e_{c}$ is the estimated back-EMF.

If the position error is a small value close to 0 , the $\sin \Delta \theta \approx$ $\Delta \theta, \cos \Delta \theta \approx 1$ assumptions can be used, and Equation (5) can be expressed as Equation (6).

$$
\left[\begin{array}{l}
\Delta i_{\gamma}^{n+1} \\
\Delta i_{\delta}^{n+1}
\end{array}\right]=\left[\begin{array}{c}
i_{\gamma}^{n+1}-i_{\gamma M}^{n+1} \\
i_{\delta}^{n+1}-i_{\delta M}^{n+1}
\end{array}\right]=\frac{T}{L_{s}}\left[\begin{array}{c}
e \cdot \Delta \theta \\
-\left(e-e_{c}\right)
\end{array}\right] .
$$

As shown in Equation (6), the estimated back-EMF $e_{c}$ and the position error $\Delta \theta$ for estimating the rotor position are obtained by using the difference between the measured current and the estimated current. Thus, the back-EMF(7) is estimated using the $\delta$-axis current error $\Delta i_{\delta}$. The rotor position (Equation (8)), and the rotor speed (Equation (9)) are obtained by using the $\gamma$-axis current error.

$$
\begin{aligned}
& e_{c}^{n+1}=e_{c}^{n}-K_{e} \Delta i_{\delta}^{n} \\
& \theta_{c}^{n+1}=\theta_{c}^{n}+\frac{e_{c}^{n+1}}{K_{E}}+K_{E} \Delta i_{\gamma}^{n} \\
& \dot{\theta}_{c}^{n+1}=\frac{\theta_{c}^{n+1}-\theta_{c}^{n}}{T}=\frac{e_{c}^{n+1}}{K_{E}}+\frac{K_{\theta}}{T} \Delta i_{\gamma}^{n} .
\end{aligned}
$$

\section{COMPensation Algorithm For Stator RESISTANCE ERROR}

\section{A. Rotor position error due to stator resistance errors}

When analytical motor modeling is not accurate, a rotor position error occurs because the current model-based sensorless algorithm needs information on the error between the measured current and the estimated current to obtain the rotor position. So, accurate motor modeling is crucial to the current model-based sensorless algorithm.

For accurate motor modeling, the stator resistance variation under a variety of conditions, the inductance variation caused by iron core saturation, and the back-EMF variation depending on demagnetization are important factors. Especially in the application of sensorless control to home-appliances, the temperature around the PMSM goes up and down when the machine's operating stage changes. In the case of temperature variation, the stator resistance variation during the sensorless control has a significant effect on the rotor position error. Thus, in this paper, the stator resistance variation is mainly considered for sensorless control in home-appliance applications.

To mathematically analyze the rotor speed error caused by the stator resistance error, it is assumed that there is no error 


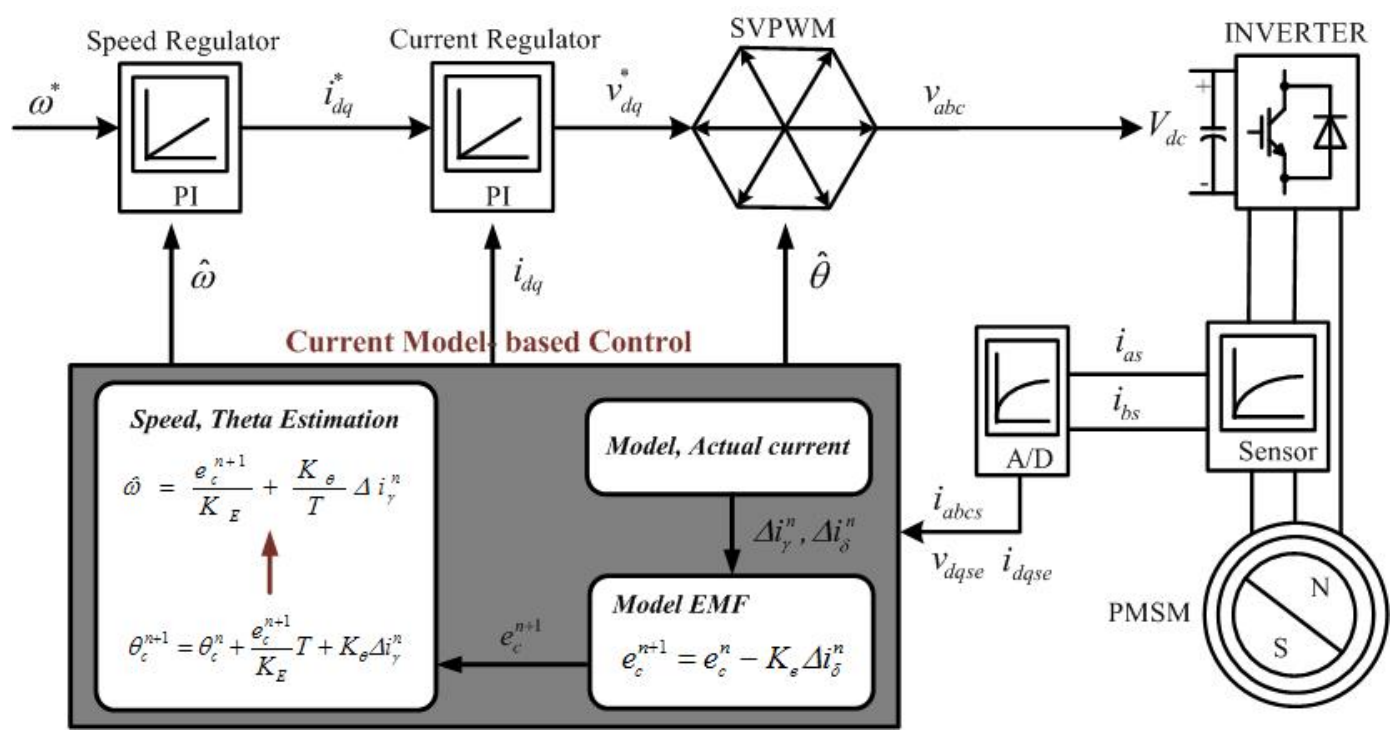

Fig. 2. Block diagram of current model-based algorithm.
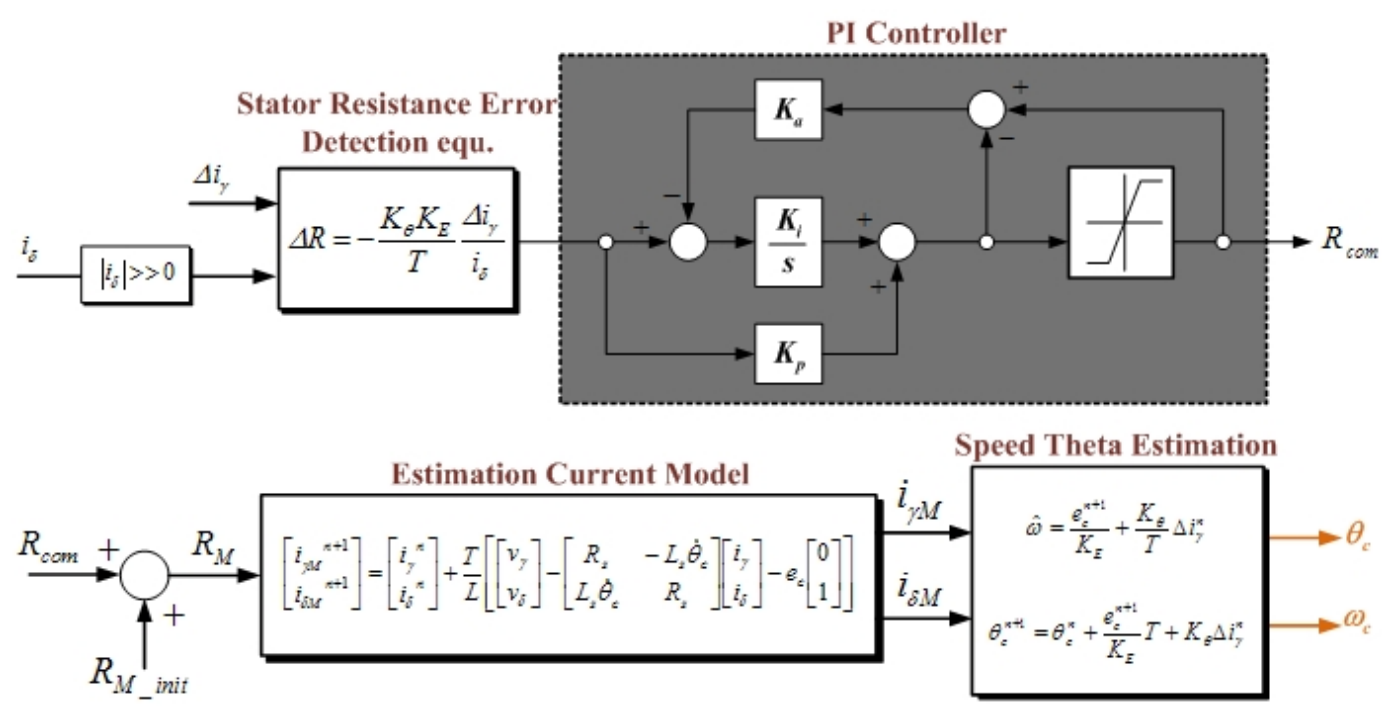

Fig. 3. Sensorless block with proposed stator resistance error compensator.

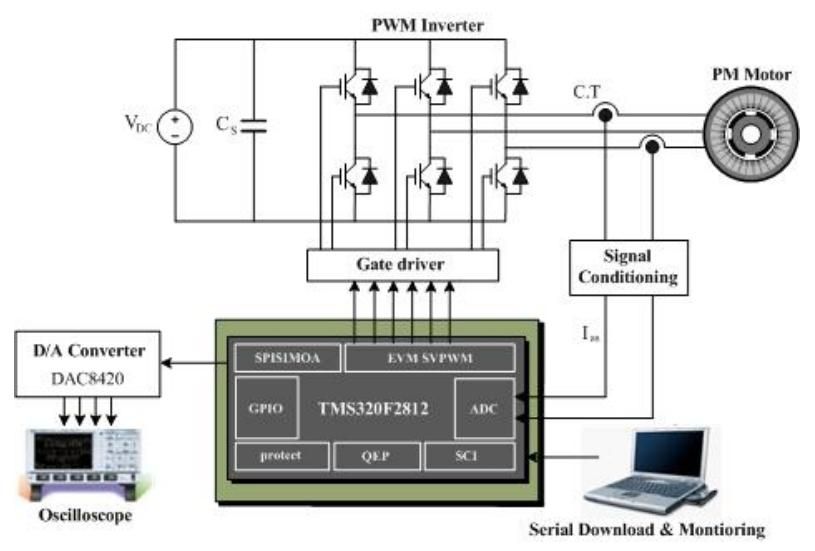

Fig. 4. Configuration of the system.

steady state response. Then, the equation of the error between the actual current and the model current is obtained as follows:

$$
\left[\begin{array}{c}
\Delta i_{\gamma M}^{n+1} \\
\Delta i_{\delta M}^{n+1}
\end{array}\right]=\left[\begin{array}{c}
i_{\gamma}^{n+1}-i_{\gamma M}^{n+1} \\
i_{\delta}^{n+1}-i_{\delta M}^{n+1}
\end{array}\right]=\frac{T}{L}\left[\begin{array}{c}
e \cdot \Delta \theta-i_{\gamma} \Delta R \\
-\left(e-\left(e_{c}-i_{\delta} \Delta R\right)\right)
\end{array}\right]
$$

where, $\Delta R=R_{s}-R_{M}$ is the stator resistance error.

When, the steady-state response relation $\theta_{c}^{n+1}=\theta_{c}^{n}+\dot{\theta} \cdot T$ is applied to Equation (10) as follows:

$$
\dot{\theta} \cdot T=\frac{e_{c}^{n+1}}{K_{E}} T+K_{\theta} \Delta i_{\gamma}^{n}
$$

Equation (11) can expressed as:

$$
K_{\theta} \Delta i_{\gamma}=-\frac{T}{K_{E}} i_{\delta} \Delta R .
$$

When $\Delta i_{\gamma}$ is replaced by Equation (10), Equation (12) can be expressed as the equation below. This equation expresses 
the rotor position error affected by the stator resistance error in the steady-state.

$$
\Delta \theta=-\frac{1}{e}\left\{\frac{L}{K_{\theta} K_{E}} i_{\delta} \Delta R-i_{\gamma} \Delta R\right\} .
$$

In general PMSM vector control, when the $d$-axis current is controlled to 0 , and with the result that $i_{\gamma}$ is converged to 0, Equation (10) can expressed as Equation (14).

$$
\Delta \theta_{R}=-\frac{L}{\dot{\theta} K_{E}^{2} K_{\theta}} i_{\delta} \Delta R .
$$

By expressing Equation (14) in terms of $\Delta i_{\gamma}$, the stator resistance error is directly obtained as below:

$$
\Delta R=-\frac{K_{\theta} K_{E}}{T} \frac{\Delta i_{\gamma}}{i_{\delta}} .
$$

\section{B. Proposed compensation algorithm}

If $\Delta R$ of the stator resistance can be compensated to 0 , the error $\Delta \theta_{R}$ of the rotor position, which is from the stator resistance error at the steady-state, can be converged to 0 . To compensate $\Delta R$ to 0 , as in Equation (14), the equation for detecting the error of the stator resistance, is used.

Fig. 3 shows a block diagram for the sensorless control including the stator resistance compensation algorithm. As expressed in Fig. 3, the stator resistance error $\Delta R$ is calculated by (14) and then the compensation value $R_{c o m}$ is obtained by a PI-controller. To apply the new stator resistance value $R_{M}, R_{\text {com }}$ is compensated on $R_{M_{-} \text {init }}$ which is applied to the estimated current equation. When $\Delta R$ is compensated to 0 , the error between the actual rotor position and the estimated rotor position in the steady-state response of the speed control converges to 0 . One thing that should be noted in this method is that, since $i_{\delta}$ (the control current along the $q$-axis) is in the denominator of Equation (14), the condition $\left|i_{\delta}>>0\right|$ should be included in the method in order to prevent the divergence of the error in the stator resistance.

\section{EXPERIMENT RESULTS}

\section{A. configuration of the system}

To verify the proposed current model-based sensorless control using a stator resistance compensator algorithm, a power conversion system was set up (Fig. 4) and tested. An 8-pole permanent magnet synchronous motor was used in the test, and the parameters of the motor are listed in table I.

The switching module used in the three-phase PWM inverter was a 600V, 30A rated IPM (Intelligent Power Module) manufactured by Mitsubishi Co. During the test, the dead time was set at 3.2us to prevent arm shorts. The phase currents were measured by a LA25-P LEM Co. current transducer. The measured phase currents were converted to digital signals, by a $12 \mathrm{bit} \mathrm{A} / \mathrm{D}$ converter, for use as controller parameters.
TABLE I

MOTOR PARAMETERS

\begin{tabular}{|l|l|}
\hline Rated power & $115 \mathrm{~W}$ \\
Rated torque & $0.5 \mathrm{~N} \cdot \mathrm{m}$ \\
Rated speed & $3000 \mathrm{rpm}$ \\
Number of pole-pairs & 2 \\
Stator resistance & $13.4159 \Omega$ \\
\hline
\end{tabular}

\section{B. Experiment results}

The experiments was driven at 250rpm to observe the transient response and the steady-state response. The stator resistance given to the estimated current equation was $10[\Omega]$. This value has a $25 \%$ difference with the actual stator resistance. The estimation gain of the rotor position $K_{\theta}$ was set at 1.0 during the test. Here, the actual values of the stator inductance and the back-EMF constant are the same as the model values. Only the stator resistance exists.

Fig. 5 and Fig. 6 show the waveforms of the $d-q$ axis current converted by the actual rotor position and the $\gamma-\delta$ axis current converted by the estimated rotor position without/with the stator resistance compensator at a $250[\mathrm{rpm}]$ reference operation and a $0.40[\mathrm{Nm}]$ load condition. In this waveform, the transient response is reduced by the compensation algorithm to almost half when compared with Fig. 5(a). Also the error gap between the $d-q$ axis current and the $\gamma-\delta$ are removed to almost zero by the compensation algorithm when compared with Fig. 5(b) and Fig. 5(c).

Fig. 7 and Fig. 8 show the waveforms of the rotor position and the rotor position error without/with the stator resistance compensator in the steady-state response. In this waveform, the rotor position error is removed and the speed response is improved through stator resistance error compensation.

Fig. 9 illustrates the compensation waveform of the stator resistance value. When the compensation algorithm is applied (4s), the initial value, $10[\Omega]$, of $R_{M}$ for the estimated current equation is converged to the actual stator resistance, 13.4[ $\Omega]$.

\section{Conclusions}

In this study, a method that reduces the rotor position error caused by a stator resistance error in current model-based sensorless control has been suggested and verified. Before proposing the algorithm, the rotor position error produced by a stator resistance error was confirmed by using mathematical analysis. Since the rotor position error due to a stator resistance error is proportional to the torque-axis ( $q$-axis) current and inversely proportional to the rotor speed, when a stator resistance error exists, the control performance in the low speed region is reduced markedly.

The proposed method detects the stator resistance error using Equation (15), a stator resistance error detection equation, and then compensates the actual stator resistance using a PIcontroller. This method has an advantage in that the algorithm is easy to implement because the equation and the derivation of the equation are simple. Through experiments, the proposed algorithm was verified. The actual rotor position was matched with the estimated rotor position in the low speed region. 


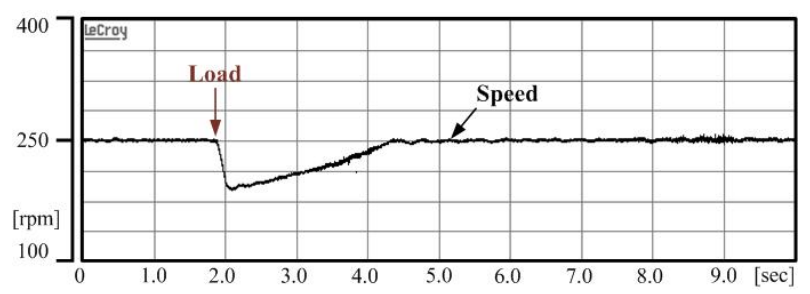

(a) Load and Real speed [rpm]

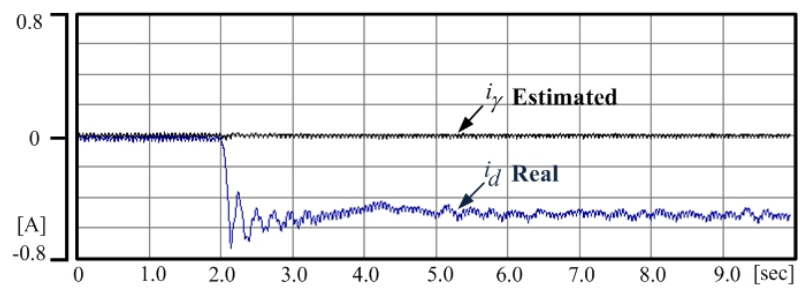

(b) $d$-axis current $[\mathrm{A}]$

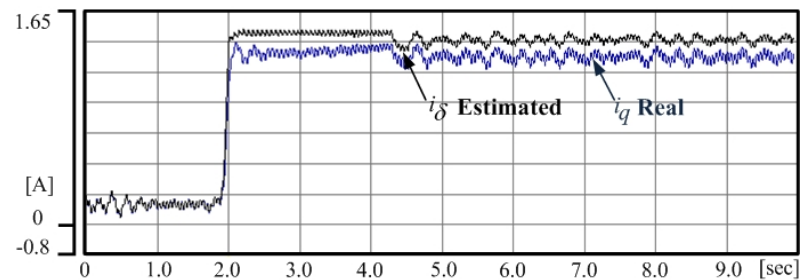

(c) $q$-axis current $[\mathrm{A}]$

Fig. 5. Speed and current waveforms without compensation.

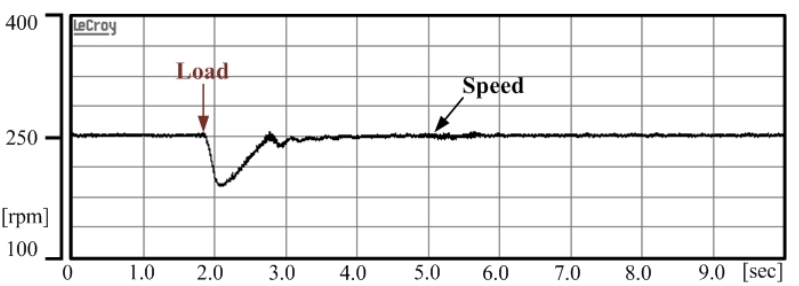

(a) Load and Real speed [rpm]

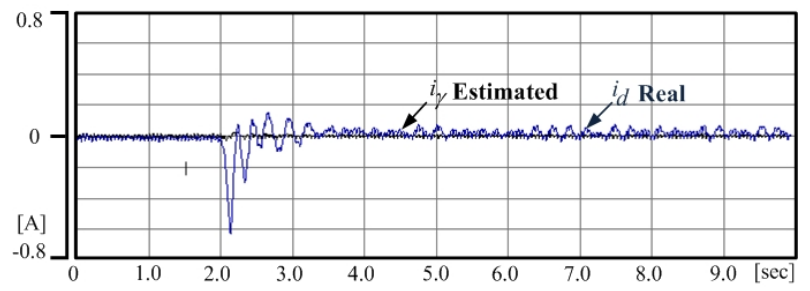

(b) $d$-axis current $[\mathrm{A}]$

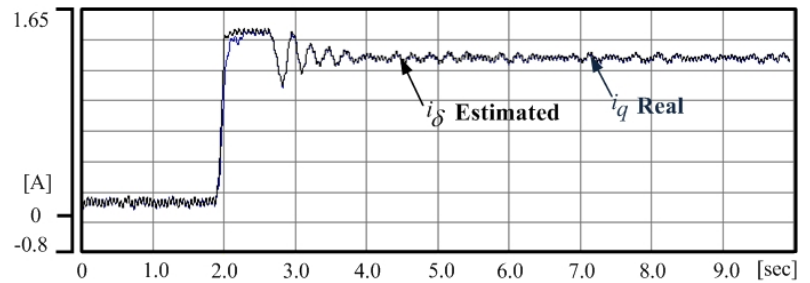

(c) $q$-axis current $[\mathrm{A}]$

Fig. 6. Speed and current waveforms with compensation.

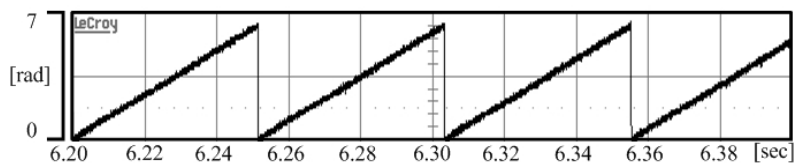

(a) Real rotor position [rad]

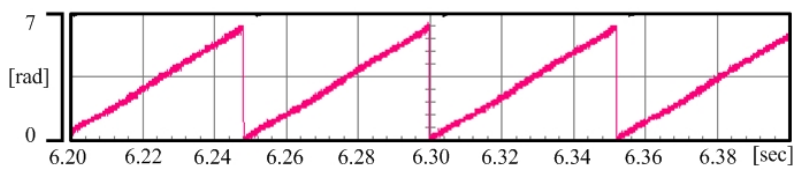

(b) Estimated rotor position [rad]

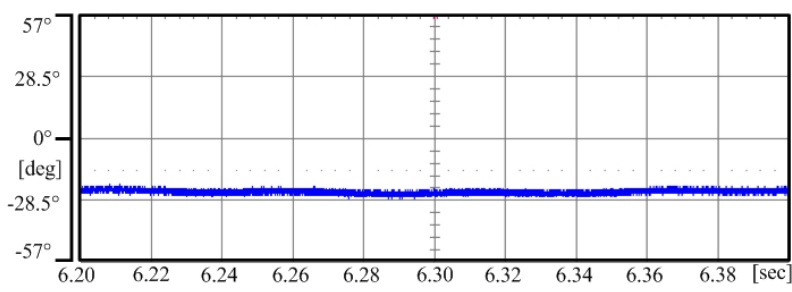

(c) Position error [deg]

Fig. 7. Position error waveforms without compensation.

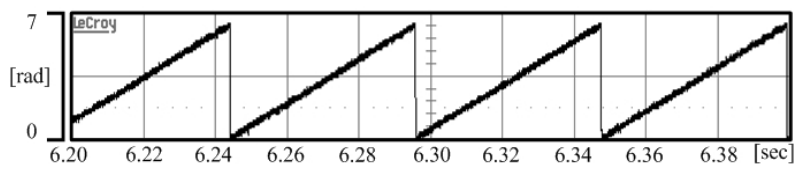

(a) Real rotor position [rad]

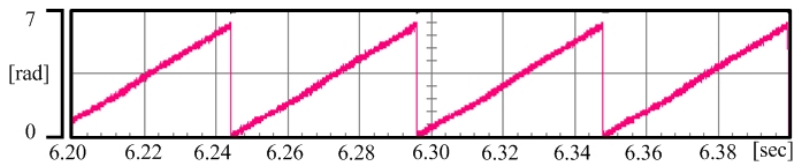

(b) Estimated rotor position [rad]

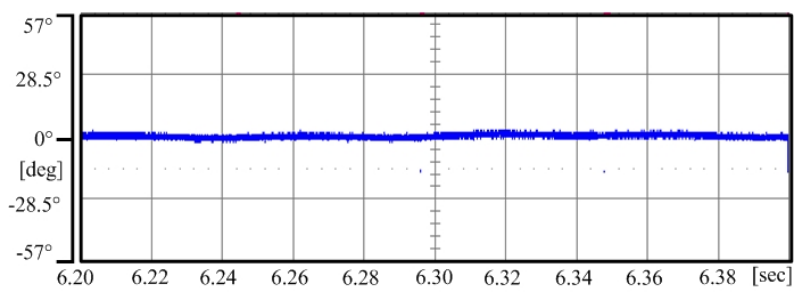

(c) Position error [deg]

Fig. 8. Position error waveforms with compensation.

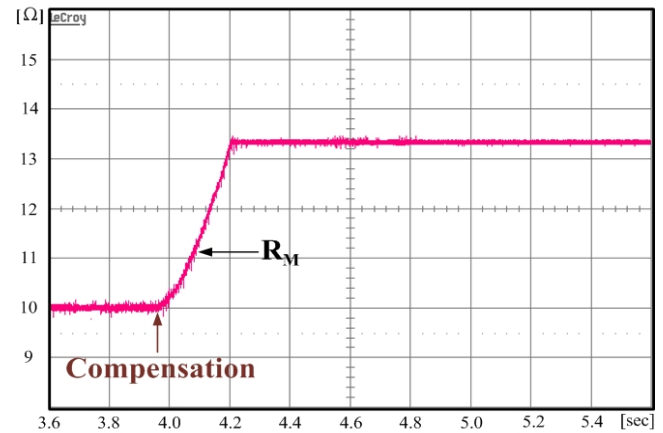

Fig. 9. Stator resistance compensation response. 


\section{REFERENCES}

[1] M. Naidy and B.K. Bose, "Rotor position estimation scheme of a permanent magnet synchronous machine for high performance variable speed drive," IEEE IAS Annual Meeting, pp.48-53, 1992.

[2] A.Consoli, A.testa "A new zero-frequency flux-position detection approach for direct-field-oriented-control drives," IEEE Transactions on Industry Applications, Vol.36, No.3, pp.797 - 804, Dec. 2000.

[3] N. Matsui, "Sensorless PM brushless DC motor drives," IEEE Trans. On Industrial Electronics, Vol.43, No.2, pp.300-308, Apr. 1996.

[4] M.J.Corley and R.D.Lorenz, "Rotor position and velocity estimation for a salient-pole permanent magnet synchronous machine at standstill and high speeds,"IEEE Trans. on Industry Applications, Vol.34, No.4, pp. 3641, Jul./Aug. 1998.

[5] M. Naidu, B. K. Bose, "Rotor position estimation scheme of a permanent magnet synchronous machine for high performance variable speed drive," Conference Record of IEEE IAS Annual Meeting, pp. 48-53, 1992.

[6] N. Ertugrul P.P. Acarnley, "A new algorithm for sensorless operation of permanent magnet motors," IEEE Trans. on Industry Applications, Vol.30, No.1, pp.126-133, Jan./Feb. 1994.

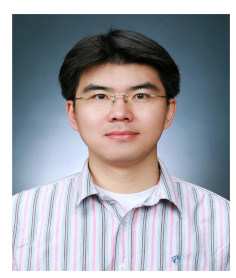

Nung-Seo Park was born in Yesan, Korea, in 1972. He received his B.S. and M.S. from Hanyang University in 1996 and 1998, respectively, in the Department of Automotive Engineering. From 1998 to 2001, he was a Research Engineer with Daewoo Motors. Since 2001, he has been with LG Electronics and he is currently developing dishwashers. His research interests include washing motor control systems and noise reduction of washing motors.

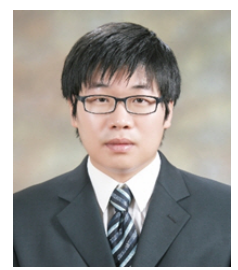

Min-Ho Jang was born in Gyungnam, Korea, in 1982 He received his B.S. and M.S. in Electrical Engineering from Pusan National University, Busan, Korea, in 2008 and 2010, respectively. Since 2010, he has been with LG Electronics, Gyungnam, Korea, where he is currently Researcher in the Advanced Control Department. His research interests include digital control systems in home appliances, motion control of washing machines and the application of microcontrollers.

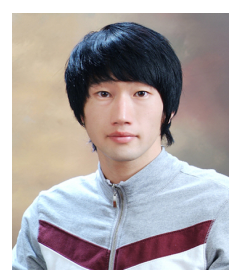

Jee-Sang Lee was born in Ulsan, Korea, in 1984. $\mathrm{He}$ received his B.S. in Electrical Engineering from Pusan National University, Busan, Korea, in 2009. He is currently working toward his M.S. at Pusan National University. His research interests include power conversion and electric machine drives.

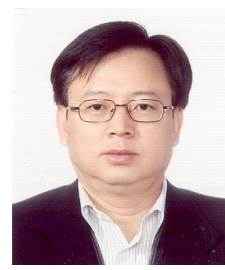

Keum-Shik Hong received his B.S. in Mechanics and Design Engineering from Seoul National University, Korea, in 1979. He received his M.S. in Mechanical Engineering from Columbia University, New York, in 1987. He also received a M.S. in Applied Mathematics and his Ph.D. in Mechanical Engineering from the University of Illinois, Urbana in 1991. Since 1993, he has been with the School of Mechanical Engineering, Pusan National University (PNU), His research interests include automotives, autonomous vehicles, APEM systems, robotics, axially moving systems, and power plant systems.

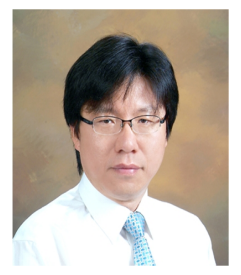

Jang-Mok Kim was born in Busan, Korea, in August 1961. He received his B.S. from Pusan National University in 1988, and his M.S. and Ph.D. from Seoul National University, Korea, in 1991 and 1996, respectively, in the Department of Electrical Engineering. From 1997 to 2000, he was a Senior Research Engineer with the Korea Electrical Power Research Institute (KEPRI) Since 2001, he has been with the School of Electrical Engineering, Pusan National University (PNU), where he is currently a faculty member. In addition, he is a Research Member of the Research Institute of Computer Information and Communication at PNU. His present interests include the control of electric machines, electric vehicle propulsion, and power quality. 